\title{
Cationic Polymerization of Oxetan by an Acid Exchanged Montmorillonite Clay in the Presence of Acetic Anhydride
}

\author{
Araf Saïd Dalil, Mohammed Issam Ferrahi* and Mohammed Belbachir
}

\author{
Laboratoire de Chimie des Polymères, Département de Chimie, Faculté des Sciences, Université d'Oran Es-Sènia BP \\ $N^{\circ} 1524$ El M'Naouar, 31000 Oran, Algeria
}

\begin{abstract}
The polymerization of oxetan with acetic anhydride catalyzed by Maghnite- $\mathrm{H}^{+}(\mathrm{Mag}-\mathrm{H})$ in dichloromethan $\left(\mathrm{CH}_{2} \mathrm{Cl}_{2}\right)$ as solvant at $25^{\circ} \mathrm{C}$ was investigated. The effects of the amounts of $\mathrm{Mag}-\mathrm{H}$ and acetic anhydride on the polymerization of oxetan were studied. The polymerization yield increased as the proportions of catalyst and acetic anhydride were increased. The reactions were monitored by gel permeation chromatography and ${ }^{1} \mathrm{H}-\mathrm{NMR}$ spectroscopy.
\end{abstract}

Keywords: Maghnite, acetic anhydride, montmorillonite, oxetan.

\section{INTRODUCTION}

The use of acid-treated clays as a solid source of protons in a number of industrially significant reactions continues to be of interest because they constitute a widely available and inexpensive solid source of protons. They were widely employed as cracking catalysts until the 1960s and are still used currently in industrial processes such as the alkylation of phenols and the dimerization and polymerization of unsaturated hydrocarbons. Montmorillonites have both Brönsted and Lewis acid sites and when exchanged with cations having a high charge density, such as protons, they produce highly-active catalysts for acid-catalysed reactions. Intercalated organic molecules are mobile and can be highly polarized when located in the space between the charged clay layers. Organic chemists, with synthesis in mind, have so far confined their interests mainly to swellable montmorillonite clays and almost all of the clay catalysts used have been either (a) acid-treated clays such as K-10, or (b), ionexchanged clays such as $\mathrm{Al}^{3+}, \mathrm{Cr}^{3+}$ or $\mathrm{H}^{+}$exchanged Wyoming or Texas bentonites. These acid-treated and cation exchanged clays can be regarded simply as solid acids that act as heterogeneous catalysts, with all of the advantages resulting from the easy removal of the catalyst from the product(s). Acid-treated clays, because of their high surface area and swelling properties, have also been widely used as solid supports for inorganic reagents such as potassium permanganate, thallium(III) nitrate and both copper(II) and iron(III) nitrates. The ion-exchanged clays have mostly Brönsted acidity in the interlamellar zone and thus are characterised by promoting acid-catalysed reactions, often of a bimolecular type, between protonated and neighbouring unprotonated reactants.

The purpose of this paper is to study the polymerization of oxetan and examine the catalytic activity of an Algerian proton exchanged montmorillonite clay called "Maghnite$\mathrm{H}^{+"}$ (Mag-H) [1-8], a new non-toxic catalyst. Maghnite is a

*Address correspondence to this author at the Laboratoire de Chimie des Polymères, Département de Chimie, Faculté des Sciences, Université d'Oran Es-Sènia BP N ${ }^{\circ} 1524$ El M'Naouar, 31000 Oran, Algeria; Fax: (+213) 41581413; E-mail: mohammed.ferrahi@caramail.com montmorillonite sheet silicate clay that is exchanged with protons to produce Maghnite- $\mathrm{H}^{+}$[1]. Mag-H can be easily separated from the polymer products and regenerated by heating to a temperature above $100{ }^{\circ} \mathrm{C}$. The effects of the relative amounts of the Mag-H and the proportion of acetic anhydride on the outcome of the polymerization are also discussed.

\section{EXPERIMENTAL}

\section{General}

Oxetan (99\%), acetic anhydride (99\%), dichloromethan $(99 \%)$ and methanol (99\%) were used as received. Molecular weights were determined by a Waters high pressure GPC instrument (Model 6000A Pump) equipped with a series of Ultra-Styragel columns (100, 500, 103, 104, 105 $\AA$ ), a 2401 Differential Refractometer and a Model 440 UV Absorbance Detector. The flow rate of the tetrahydrofuran (THF) eluent was $1 \mathrm{~mL} / \mathrm{min}$. The calibration curve was constructed with well-fractionated poly(oxetan) standards. ${ }^{1} \mathrm{H}-\mathrm{NMR}$ spectra were recorded on an AM 300 FT Bruker instrument using deuterated chloroform as solvent, and tetramethylsilane (TMS) as internal standard.

\section{Catalyst Preparation}

"Maghnite- $\mathrm{H}^{+}$xM" were prepared by a method similar to that described by Belbachir et al. [1]. Raw maghnite (20 g) was crushed for $20 \mathrm{~min}$ using a Prolabo ceramic ball grinder. It was then dried by baking at $105{ }^{\circ} \mathrm{C}$ for $2 \mathrm{~h}$. The maghnite was then weighed and placed in an Erlenmeyer flask together with distilled water $(500 \mathrm{~mL})$ and magnetically stirred maghnite/water mixture was combined with sulfuric acid until saturation was achieved. After 2 days at room temperature the mineral was washed with water until it became sulfate free and then dried at $150{ }^{\circ} \mathrm{C}$. Sulfuric acid solutions of $0.05 \mathrm{M}, 0.10 \mathrm{M}, 0.15 \mathrm{M}, 0.20 \mathrm{M}$, $0.25 \mathrm{M}, 0.30 \mathrm{M}$ and $0.35 \mathrm{M}$ concentration were used to prepare "Maghnite- $\mathrm{H}^{+} 0.05 \mathrm{M}$ ", "Maghnite- $\mathrm{H}^{+} \quad 0.10 \mathrm{M}$ ", "Maghnite- $\mathrm{H}^{+}$0.15M", "Maghnite- $\mathrm{H}^{+} \quad 0.20 \mathrm{M}$ ", "Maghnite $\mathrm{H}^{+} \quad 0.25 \mathrm{M}$ ", "Maghnite- $\mathrm{H}^{+} \quad 0.30 \mathrm{M}$ " and "Maghnite$\mathrm{H}^{+} 0.35 \mathrm{M}$ ", respectively. 
Table 1. Elementary Compositions of Proton Exchanged Samples of "Maghnite-H "

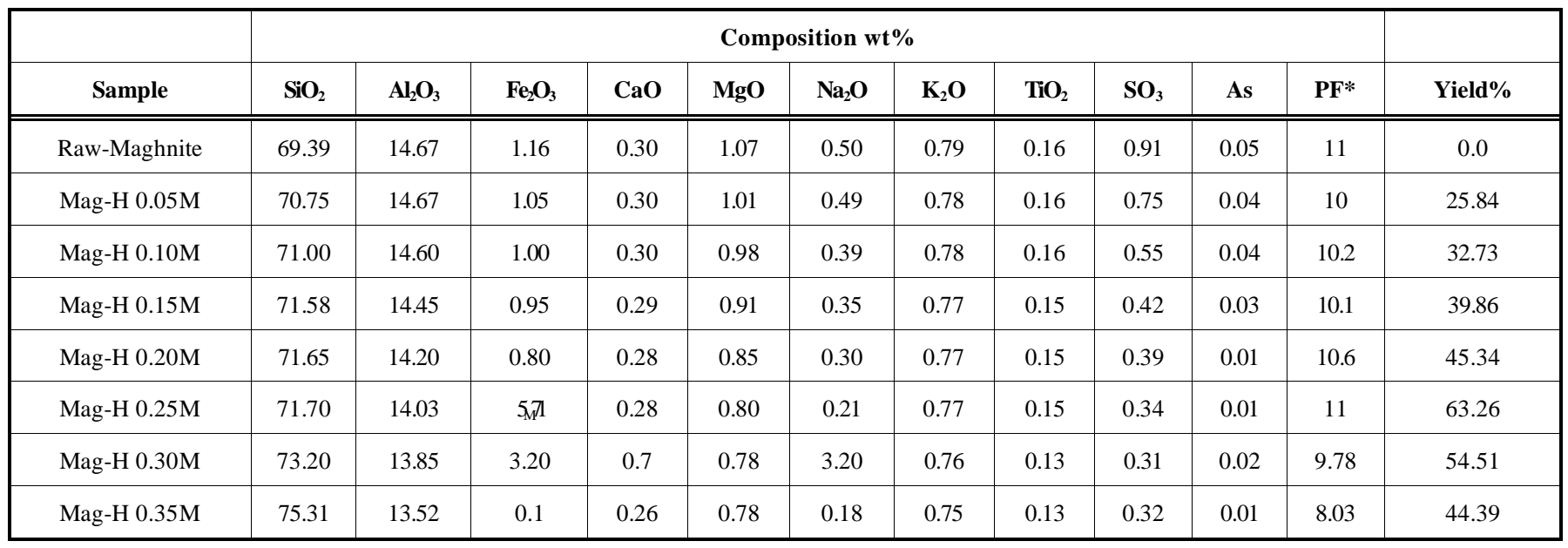

*PF : Pert in Fire.

\section{Polymerization Procedure and Polymer Characterization}

Polymerizations were carried out in stirred flasks at $25^{\circ} \mathrm{C}$. The catalyst was dried in a muffle furnace at $120^{\circ} \mathrm{C}$ overnight and then transferred to a vacuum desiccator containing $\mathrm{P}_{2} \mathrm{O}_{5}$. After cooling to room temperature under vacuum, the mineral was added to the oxetan $(0.01$ $\mathrm{mol} / \mathrm{L})$ and acetic anhydride $(5 \%)$ mixtures previously kept in the stirred flask at $25^{\circ} \mathrm{C}$. After the required time was reached, an aliquot of the reaction mixture was then removed in such a manner as to exclude any clay mineral and slowly added to methanol with stirring. The precipitated polymer was filtered off, dried under vacuum and weighed. The polymers were redissolved in dichloromethan and precipitated in methanol for characterization and molecular weight measurements.

\section{RESULTS AND DISCUSSION}

\section{Catalyst Structure}

The elementary analysis of the selected samples obtained using XRF and the yields obtained from the reaction of $5 \%$ of each sample with $0.01 \mathrm{~mol} / \mathrm{L}$ of oxetan and $5 \%$ of acetic anhydride for 6 hours in polymerization at $25^{\circ} \mathrm{C}$ are shown in Table 1.

The best yield was obtained using "Maghnite-H+ $0.25 \mathrm{M}$ ", so for this reason this sample was used to study the effects of catalyst and acetic anhydride proportions on polymerization. Acid treatment of "Raw-Maghnite" causes a reduction in octahedral content $\left(\mathrm{Al}_{2} \mathrm{O}_{3}\right)$ and resulted in an increase in the proportion of silica $\left(\mathrm{SiO}_{2}\right)$ observed.

\section{Polymerization and Product Characterization}

The results of polymerization experiments of $0.01 \mathrm{M}$ oxetan with $5 \%$ of acetic anhydride induced by "Maghnite$\mathrm{H}^{+} 0.25 \mathrm{M} "$ are reported in Table 2. For all these experiments the temperature was kept constant at $25^{\circ} \mathrm{C}$ for 6 hours.

\section{Effect of the Amount of Mag-H on the Polymerization}

We can see from Table 2 that the yield increases as the proportion of "Maghnite- $\mathrm{H}^{+} 0.25 \mathrm{M}$ " increases (experiments 1,2). Table $\mathbf{3}$ shows the effect of the amount of Mag-H on the polymerization yield. Indeed, using various amounts of Mag-H: 5 and $10 \%$ by weight, the polymerization was carried out in dichloromethan at $25{ }^{\circ} \mathrm{C}$. The polymerization yield increased with the amount of Mag-H, thus clearly showing the effect of Mag-H as a catalyst. This phenomenon is probably the result of an increase in the number of "initiating active sites" responsible of inducing polymerization, a number that is prorata to the amount of catalyst used a reaction.

\section{Effect of the Proportion of Acetic Anhydride on the Po- lymerization}

The addition of acetic anhydride to the mixture creates chain ends unable to take part in polymerization and consequently the problem of reproducibility of molecular weight does not exist, allowing the existence of a stable polymer.

The data in Table 2 shows that the yield increases as the proportion of acetic anhydride increases (experiments $1,3)$. This result is due to a multiplication of the active cen-

Table 2. Polymerization of Oxetan with Acetic Anhydride Induced by "Maghnite- $\mathrm{H}^{+} \mathbf{0 . 2 5 M "}$

\begin{tabular}{|c|c|c|c|c|}
\hline Experiment & [AA](\%) & $\begin{array}{c}\text { Maghnite-H } \\
\mathbf{0 . 2 5 M ( \% )}\end{array}$ & Yield (\%) & Mw \\
\hline \hline 1 & 5510 & 5 & 63.2671 .6867 .84 & 447415379 \\
\hline
\end{tabular}

[AA] : Acetic anhydride. 
Table 3. Polymer Yields with Time for $0.01 \mathrm{~mol} / \mathrm{L}$ of Oxetan, $5 \%$ of Acetic Anhydride

\begin{tabular}{|c|c|c|c|c|c|}
\hline Time(hours) & $\mathbf{2}$ & $\mathbf{3}$ & $\mathbf{4}$ & $\mathbf{5}$ & $\mathbf{6}$ \\
\hline Amount of Maghnite $\mathbf{H}^{+}$ & \multicolumn{3}{|c|}{} & & \\
\hline \hline $5 \% 10 \%$ & 9.31 & 14.6721 .23 & 31.4637 .86 & 41.2749 .15 & 63.2671 .68 \\
& 16.52 & & & \\
\hline
\end{tabular}

Table 4. Polymer Yields with Time for $0.01 \mathrm{~mol} / \mathrm{L}$ of Oxetan, and $5 \%$ of Maghnite-H+ 0.25M.

\begin{tabular}{|c|c|c|c|c|c|}
\hline Time(hours) & $\mathbf{2}$ & $\mathbf{3}$ & $\mathbf{4}$ & $\mathbf{5}$ & \\
\hline Acetic Anhydride & \multicolumn{5}{|c|}{} \\
\hline \hline $5 \% 10 \%$ & 9.3112 .97 & 14.6719 .75 & 31.4633 .86 & 41.2745 .27 & 63.2667 .84 \\
\hline
\end{tabular}

Table 5. Product Analysis by ${ }^{1}$ H-NMR Spectroscopy

\begin{tabular}{|c|c|c|c|}
\hline Proton Type & (a) & (b) & (c) \\
\hline \hline $\mathbf{5}$ in ppm & 1.7 & 2.2 & 3.5 \\
\end{tabular}

ters. However, the molecular weight increases when the proportion of acetic anhydride is reduced. This result is due to an increase in the number of methyl groups at the extremities of the chains that block the growth of polymer chains. These observations were followed up in a series of detailed experiments in which the variation of yield with time has been observed at two levels of acetic anhydride. Table 4 shows that increasing the acetic anhydride amounts gave higher yields.

\section{Characterization of Products}

An investigation was devoted to the analysis of the polymer from experiment 1 in Table 2 by $300 \mathrm{MHz}{ }^{1} \mathrm{H}$ NMR spectroscopy (Table 5). The reaction taking place is shown in the following scheme:

According to the work published by Hamilton and Semlyen [9] and Vivas and Contreras [10] the $300 \mathrm{MHz}{ }^{1} \mathrm{H}$ NMR spectra (in deuterated chloroform, Fig. 1) showed three sets of peaks, corresponding to the methyl groups of

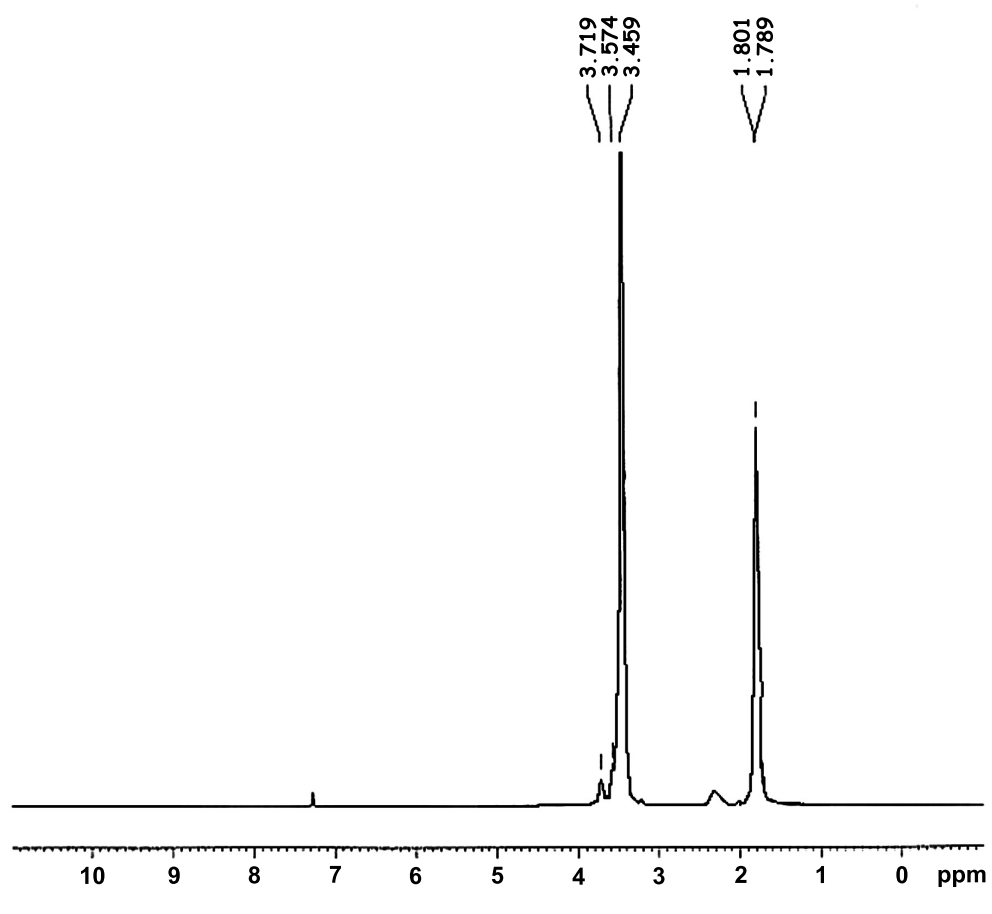

Fig. (1). ${ }^{1} \mathrm{H}-\mathrm{NMR}$ spectra of the poly(oxetan) product of experiment 1 in Table 3 . 
the main chain at $2.2 \mathrm{ppm}$, the $\beta$ methylene groups at 1.7 ppm, the $\alpha$ methylene groups at $3.5 \mathrm{ppm}$.

\section{CONCLUSIONS}

In conclusion, we have found that acid-exchanged maghnite is effective as acidic catalyst for the ring opening polymerization of oxetan. The polymerization catalysed by Mag-H+, in the presence of acetic anhydride proceeds by activated monomer mechanism (AMM) to yield Poly (oxetan). The polymerization proceeds smoothly, and a simple filtration is sufficient to recover the catalyst.

\section{REFERENCES}

[1] Belbachir, M.; Bensaoula A. Composition and method for catalysis using bentonites. U.S.Patent 6274527, 2001.

[2] Yahyaoui, A.; Belbachir, M.; Hachemaoui, A. Cationic polymerization of 1,2-epoxypropane by an acid exchanged montmorillonite clay in the presence of ethylene glycol. Int. J. Mol. Sci., 2003, 4, $572-585$.
[3] Ballantine, J.A.; Davies, M.; Purnell, H. Chemical yields using sheet silicates: novel interlamellar dehydrations of alcohols to ethers and polymers. J. Chem. Sci., 1981, 6, 427-428.

[4] Odian, G. Principles of polymerization. Wiley, New York, 1991.

[5] Madejovà, J.; Bednànikovà, E.; Komadel, P.; Cicel, B. in Proc. 11th Conference of Chemistry, Miner and Petrol, Ceske Budéjovica 1990. Konta, J. Ed. Charles University, Prague, 1993; 267

[6] Ferrahi, M.I.; Belbachir, M. Polycondensation of tetrahydrofuran with phthalic anhydride induced by a proton exchanged montmorillonite clay. Int. J. Mol. Sci., 2003, 4, 312-325.

[7] Ferrahi, M.I.; Belbachir, M. Synthesis of cyclic polyesters of poly(oxybutylene oxymaleoyl). J. Polym. Res., 2005, 12, 167-171.

[8] Ferrahi, M.I.; Belbachir, M. Preparation of poly(oxybutyleneoxymaleoyl) catalyzed by a proton exchanged montmorillonite clay. Molecules, 2004, 9, 968-977.

[9] Hamilton, S.C.; Semlyen, J.A. Cyclic polyesters: 5. Cyclics prepared by poly(decamethylene terephthalate) ring-chain reactions. Polymer, 1997, 38, 1685-1691.

[10] Vivas, M.; Contreras, J. Ring-opening polymerization of $\varepsilon$ caprolactone initiated by diphenylzinc. Eur. Polym. J., 2003, 39, 43-47.

(c) Dalil et al.; Licensee Bentham Open.

This is an open access article licensed under the terms of the Creative Commons Attribution Non-Commercial License (http://creativecommons.org/licenses/by-nc/3.0/) which permits unrestricted, non-commercial use, distribution and reproduction in any medium, provided the work is properly cited. 